\title{
Welcome to Pathfinder
}

\section{Erin Ballantyne ${ }^{1}$}

\author{
${ }^{1}$ Editor-in-Chief, Pathfinder Journal
}

\section{To Cite:}

Ballantyne, E. (2020). Welcome to Pathfinder [Editorial]. Pathfinder: A Canadian Journal for Information Science Students and Early Career Professionals, 1(2), 1-2. https://doi.org/10.29173/pathfinder27

\section{Abstract}

Some opening remarks on the publication of our first regular issue including brief explanation of our name and founding principles and listing of persons to whom thanks are most certainly due.

Keywords: editorial

$\mathrm{O}$ $\mathrm{n}$ behalf of the editorial team and myself, I am delighted to announce the publication of the inaugural issue of Pathfinder: A Canadian Journal for Information Science Students and Early Career Professionals.

Pathfinder was founded in 2018 to fulfill a vision of a scholarly venture in which all library and information studies students, both on-campus and online, at the University of Alberta's School of Library and Information Studies could all participate equally. However, as our founding team explored the publishing landscape, we noted where gaps existed and our scope quickly widened not only to a national scale but also to the many professional foci that LIS education encompasses including, but not limited to, archival studies and technician programs. Our core drive is to connect emerging information professionals through interdisciplinary conversations.

We chose Pathfinder as a name for the journal because of its association as a synonym to research guides, study guides, subject guides, and the like. These collections of resources are starting points for intellectual or pedagogical journeys and, importantly, they are not tied to any one discipline in libraries and information studies. Rather, they are created, maintained, accessed, and disseminated by many in our community to highlight critical, accurate, and trustworthy information. Something that, I am sure we would all agree, is sorely needed in these times. As such and simply put, we hope that this journal acts as a pathfinder, as a curated tool, leading users towards discovery by making use of the best resources on offer.

And I do truly believe that the articles in this issue are an excellent representation of the diversity of areas of research and interest in our community. In these manuscripts, authors 
grapple with the continuing oppression of Indigienous and LGBTQIA2S+ communities, with our fundamental rights to accessing information, with exploring real world applications for scholarly research, and understanding the complexities of terminology in interdisciplinary study. All timely, all important.

On the occasion of our first issue, the journal would like to acknowledge the contributions of founding editor Caitlin MacRae and the work of the journal creation team including Aggie Sliwka, Alexis Poeschek, Amanda Lepage, Christopher Flint, Denise Rechlo, Graeme Tennant, Jennifer Coupe, Jessica Frechette, Kaitlyn Grant, Karina Dunna, Kathleen Oliver, Kathy Wise, Ren Milmine, Sanja Gidakovic, and Ashley Edwards who were all instrumental in determining the scope and editorial policies of the journal. We would also like to thank all of the authors who took the time to submit articles to Pathfinder with the faith that the journal would grow around them. I hope that your experience with the peer-review process was a beneficial one. Finally, thanks are due to Pathfinder's editorial team and peer review teams and the University of Alberta Library Publishing and Digitization Team who have generously donated their time to see this project to success. I appreciate their professionalism through the growing pains of a journal's first issue.

With recent events, I know that it was no coincidence that our first special issue in collaboration with the Forum For Information Professionals was on the topic of resilience; everyone involved in our journey has not only accepted the uncertainty of change but put up with the chaos of life admirably. It is my dearest hope that the continued publication of Pathfinder will remain as flexible and open to growth in years to come to best support the academic pursuits of students and early professionals across Canada. 